\title{
Salutogenesis in Prison
}

\author{
James Woodall, Nick de Viggiani, and Jane South
}

\section{Introduction}

An increasing shift in the international discourse on Prison Health towards a salutogenic perspective has emerged with the ever-expanding interdisciplinary public health movement that recognises prison health to be a significant arm of public health. This shift is reflected in the World Health Organization's (WHO) healthy prisons ethos that advocates tackling health and social inequality and harnessing the social determinants of health to create settings where effective health improvement can occur. In the spirit of the Ottawa Charter for Health Promotion, this means "enabling people to increase control over" their health through supportive environments where they can harness key social and structural resources that enable them to attain health (WHO, 1986). The prison public health movement recognises that health inequalities disproportionately impact criminal justice populations (WHO, 2020). Prisoners, in particular, experience comparatively higher prevalence of physical and mental ill-health, disability and preventable communicable and noncommunicable disease than their host populations. This is the WHO's (2016: 1) statement on prisoner health:

The health status of prisoners is almost always inferior to that of people at liberty. The risk of becoming seriously ill tends to be much higher in prison than in the general population

The high levels of health need are associated with a further set of challenges around inequality. Communities with relatively high levels of material deprivation and socioeconomic inequality are significantly over-represented within criminal justice systems and settings (Cavadino \& Dignan, 2006; Marmot et al., 2020). "Offenders" are, moreover,

J. Woodall $(\varangle) \cdot$ J. South

School of Health and Community Studies, Leeds Beckett

University, Leeds, UK

e-mail: j.woodall@leedsbeckett.ac.uk

N. de Viggiani

Department of Health and Social Sciences, University of the West

of England, Bristol, UK highly likely to lack protective predispositions that prevent them from becoming involved in or affected by crime, and to avoid being exposed to criminogenic environments (Morse, 1975). Ewing (2018: 29) furthermore argues that individuals who experience social disadvantage - such as poverty, lack of educational opportunity, racial oppression or interpersonal abuse, particularly in combination - are at higher risk of entering criminal justice agencies or settings. This was recently emphasised by the UK charity Revolving Doors (2017), which argued that "the health, economic and social inequalities faced by the population in contact with the criminal justice system are stark and striking."

Persons who experience "criminogenic disadvantage" (Ewing, 2018: 29) may find it considerably difficult to avoid the adverse health and social consequences of inequality. It is widely acknowledged that this reflects both the relatively poor material and socioeconomic circumstances of prisoners' pre-imprisonment and the harmful and depriving effects of imprisonment and other criminal justice processes.

The over-arching goal for prison health is therefore to develop "upstream" public health strategies that enable salutogenesis - or health creation - and to negate deleterious, harmful and unjust effects of criminal justice processes and reverse criminogenic potential within communities at risk of offending. In this chapter, it is argued that a salutogenic prison health ethos should provide the conditions to develop effective and meaningful public health and health promotion strategies for people in criminal justice or correctional settings. This means developing healthy correctional policies, re-orientating custodial and non-custodial corrections environments and enabling prisoners and prison staff to attain power and agency in accessing resources to improve their health chances and health outcomes. A healthy prisons approach fundamentally draws the focus away from indicators of disease, ill-health and disability and towards a salutogenic perspective (Baybutt \& Chemlal, 2016). This is not to say that healthcare management is not important but to suggest that prison-based public health and health promotion are much more than techniques to prevent ill-health. 
This chapter addresses three key objectives. First, it critically reviews the regressive historical, biomedical and individualistic position that prison health has occupied internationally, against which reactive preventive policies and practices have become anchored. It examines how this traditional position has suited the dominant neoliberal political standpoint of western societies, with its limited scope to engage and advance a healthy prisons agenda. Second, this chapter reviews the healthy prisons ethos and its embracement of salutogenic principles, emphasising the instrumental role of the WHO in operationalising this agenda. Third, this chapter explores how to practically create salutogenic prisons but being mindful of the inherent challenges of delivering a progressive prison health agenda across an international context, where security and control services to routinely disempower and disable prisoners and undermine attempts to rebuild lives.

\section{The Pathogenic Approach Towards Prison Health Policy and Practice}

"Prison health" is commonly understood and interpreted as a biomedical construct pertaining to the commissioning, management and prevention of disease, illness and disability within prison populations. Arguably, this perspective reflects the somewhat outdated paradigm of public health medicine that considers the prevention of communicable and noncommunicable disease to be the primary role of public health within prison contexts. Such an approach fails to acknowledge the broad social, economic and environmental context of health and illness, and is individualistic in orientation, associating prison health with the individual prisoner, offender or agent rather than with the circumstances surrounding the individual - the prison, correctional setting, criminal justice system or wider society. A healthy or unhealthy prison, after all, should refer as much to the social and material fabric of the prison, and the experience of imprisonment, as much as to the health of the prisoner. The response of correctional services is logically to treat or manage individual prisoners with respect to their individual criminogenic or pathogenic/healthcare needs. This reactive and reductionist version of prison health draws upon health professionals to intervene at an individual clinical or behavioural level to "fix the problem" rather than to address the underlying causes. It serves to draw resources away from addressing fundamental root causes of poor health and offending - those wider social and criminogenic determinants, inequalities and prerequisites for health. This was aptly summed up by Roberts (2009), who has argued that "the process of criminal justice mystifies rather than clarifies what is harmful in society and might be done about it."
Hence there is a longstanding tradition within correctional services across the world to anchor prison health within the biomedical paradigm and consequently to situate prison health policies and practices within a healthcare context. This was, for instance, reflected in the development of the US correctional health system in the 1930s, with the establishment of the first Medical Center for Federal Prisoners in Springfield in 1933; this service was "dedicated solely" to caring for the diseased and the "broken bodies and minds of offenders" (Bosworth, 2002: 79). This emphasis on medical and psychiatric treatment was highlighted by Sim (1990) in his influential debate on medical power in prisons. It was colourfully illustrated by Morris and Morris (1963: 193) in their study of Pentonville prison in London in the 1960s:

For the prison, health is essentially a negative concept; if men are not ill, de facto they are healthy. While most modern thinking in the field of social medicine has attempted to go further than this, for the prison medical staff it is not an unreasonable operational definition

In some ways, this adherence to the biomedical and psychiatric paradigms is not surprising given the negative health consequences of imprisonment and correctional processes more generally. Much debate, commentary and evidence have highlighted the harms that imprisonment can facilitate. Indeed, Roberts (2009) argued that criminal justice systems orchestrate harmful effects to society through their negative impacts on the social, material and economic potential of the most disadvantaged and in terms of their health and wellbeing. As far back as the mid-nineteenth century, the social reformer Jeremy Bentham (1864: 351-352) referred to prisons as pathogenic environments that:

\footnotetext{
... include every imaginable means of infecting both body and mind. Consider merely the state of forced idleness to which prisoners are reduced ... Want of exercise enervates and enfeebles their faculties, and deprives their organs of suppleness and elasticity
}

Gresham Sykes (1958: 79), in his ethnographic research of the mid-twentieth-century US penitentiary system, similarly observed how:

The individual's picture of himself as a person of value - as a morally acceptable, adult male who can present some claim to merit in his material achievements and his inner strength begins to waver and grow dim

The United Nations' International Covenant on Economic, Social and Cultural Rights (UN General Assembly, 1966) asserted the right to all citizens of the world "to the enjoyment of the highest attainable standard of physical and mental health." This was reflected in Rawls' (1973) egalitarian argument that a socially just society is one: 
... in which basic human needs are met, unnecessary stress is reduced, the competence of each person is maximised, and threats to well-being are minimised; and where value is recognised in enabling each person to have a fair share of benefits and burdens resulting from their participation in society, or 'social cooperation'

This was a position echoed by the WHO Office of the European Region (1985). They asserted that all EU member states should improve the level of health of the most disadvantaged groups within their societies by providing equitable health policies that extend beyond the meeting of basic healthcare needs. This was an interpretation of the notion of "equivalence" that implies not only reducing a population's observed health differences but eliminating those health needs arising from avoidable or unfair societal determinants (Charles \& Draper, 2012; Ismail et al., 2019). This was also recently conveyed by the WHO Commission on the Social Determinants of Health:

The social conditions in which people are born, live and work are the single most important determinants of good health or ill health, of a long and productive life, or a short and miserable one. (Marmot et al., 2008)

These ethical principles apply as much to prisoners as to other vulnerable groups. Indeed, the UN's 1966 International Covenant underpinned its 1990 Basic Principles for the Treatment of Prisoners (United Nations, 1990), stating that prisoners should be provided with access to health services equivalent to those provided for the general population of their respective host countries.

In the United Kingdom, prison health services are commissioned to address prisoners' observed healthcare needs; these are routinely measured through healthcare needs assessments, screening and public health surveillance. This principally reactive approach tends to reflect more the needs of the criminal justice system, of the health services and the State since it seeks to "contain" the problem rather than prevent it and avoids measures to address the deeper-seated needs of society more broadly. Healthcare services are therefore commissioned to respond to acute disease, illness or disability that present within prison populations (HMIP, 1996). They essentially detect, manage and treat morbidity arising from acute and longstanding non-communicable and communicable disease (de Viggiani, 2006a). This reflects a preoccupation with an interpretation of prison health that is fundamentally individualistic, which results in an approach to health promotion that is reactive to and pre-occupied with lifestyle issues. Interventions believed to be effective in tackling risky behaviours are routinely commissioned and located within healthcare services (Department of Health, 2002: 2). This inevitably means that prison authorities interpret prisonbased health promotion as an exclusive educational role for healthcare professionals. Consequently, opportunities to engage prison personnel in progressive partnership work across conventional professional boundaries are not explored where there would be potential to promote and improve health at a system-wide level (Meek, 2018). Squires (1996: 1161), moreover, has argued that:

To focus only on the physical and mental illness of prisoners, which is the likely focus of any agency given the job of commissioning health services for prisoners, would be to ignore the role of non-health professionals and agencies inside and outside prison in promoting prisoners' health and well-being.

Therefore, despite recent and ongoing prison health policy rhetoric, prison-based health promotion remains firmly aligned with prison healthcare services and is led mainly by healthcare personnel, particularly those involved in delivering acute services, rather than being seen as the responsibility for the whole organisation. The majority of male prisons inspected in England and Wales in 2018, for example, were exceptionally proficient at managing and screening for diseases for people in prison. Analysis suggested that $88 \%$ of prisons enabled easy access to health checks, disease prevention and screening programmes. There were few instances where support and healthcare provision were deficient in this domain. Where mentioned in the reports, prisons were highly effective at managing outbreaks. They had established clear protocols to minimise any health impacts caused by, for example, communicable diseases and diarrhoea and vomiting (Woodall \& Freeman, 2019). Smith (2002) has noted how often normative health need, that is, expert opinion, has governed much prison health policy and planning. Even in Scotland, where policy actively supports the participation of prisoners in health promotion planning, their involvement is limited, and exploration of their views on health is scant (Graham, 2007). The contribution of broader agencies associated with prison governance seems to reinforce a pathogenic approach to public health and health promotion.

Assessment of health provision by Her Majesty's Inspectorate of Prisons for England and Wales (HMIP), moreover, reveals a very narrow and biomedical position (Woodall \& Freeman, 2019). This is unfortunate given that HMIP is considered to be an influential body with a highly valued authoritative voice, especially since it has unconditional access to all areas of an institution and can arrive unannounced (Hardwick, 2016). Prison inspections draw on a range of data, including a confidential survey of a representative proportion of the prisoner population; prisoner focus groups; individual interviews carried out with staff and prisoners; documentation analysis and observation by inspectors (Bennett, 2014). This methodology is recognised for its international excellence (Harding, 2006). It has "influence [that] is so pervasive that the HMIP can be said indirectly to regulate prison conditions" in England and Wales (van Zyl Smit, 2010: 532). 
As suggested, the current criteria adopted by HMIP convey a very narrow perspective on health and well-being. For example, mental health is not considered within HMIP's criteria for promoting health and well-being (there are specific criteria for assessing mental health care in prisons, but these are focused on the management of mental illness or ill-health rather than the promotion of health and well-being). Moreover, in the evolution of HMIP's inspection criteria, there do not seem to have been discussions with a wide range of stakeholders on the most suitable criteria for assessing health and well-being. Baybutt et al. (2010) have optimistically argued that the approach towards commissioning and delivering health provision in prisons has been reformed. However, the dominant discourse surrounding prison health, particularly efforts to promote health, retain a heavily skewed focus towards disease control, eradication, screening and testing. If health promotion is to be developed further in prison, then the prevention of disease and the promotion of positive health need to be more carefully balanced (Caraher et al., 2002). While it is accepted that preventive measures are included within many conceptual frameworks of health promotion (Downie et al., 1996), some would argue that a more radical approach would be for health promotion to focus primarily on advancing the health of prisoners towards the positive end of the disease-health continuum (Breslow, 1999; Brubaker, 1983; King, 1994). This unwavering fixation by prison services to focus on pathogenesis can be understood as wholly logical. For instance, it could be cogently argued that these interventions are perhaps aimed at the effective management of the prison population, rather than for promoting health benefits per se (Woodall \& Freeman, 2019).

\section{The Shift Towards Salutogenesis}

The question, "what makes people healthy?" or "what creates health?" is one of the critical pillars of salutogenesis introduced by Antonovsky (1979). A salutogenic perspective on health and well-being represented, for him, an alternative interpretation. He did not perceive a continuum between pathogenesis and well-being, as such, where health is the antithesis of illness, but rather in terms of people's capacity and ability to cope, attain resilience and harness the resources or determinants of health - to have control and agency (Mittelmark \& Bauer, 2017; Mittelmark \& Bull, 2013).

Antonovsky (1979) introduced the notion of salutogenesis at a time when the dominant paradigm in Public Health focused on disease epidemiology and risk factors in the search for causal relationships between behavioural risk, exposure or susceptibility and ill-health. He argued that essentially the creation of health is not aligned on a continuum with the causes of disease, thereby contesting the established wisdom that health is improved by reducing risk factors for disease. In his view, health is created through biological, psychosocial and material resources (General Resistance Resources) that bring consistency, structure and sense to people's lives. These could include money, knowledge, experience, self-esteem, healthy behaviour, commitment, social support, cultural capital, intelligence, traditions and view of life (Hochwälder, 2019). When individuals or groups have these resources at their disposal, there is a better chance for them to cope with the challenges of life. More important is their ability to harness these resources - achieving a strong Sense of Coherence (SOC) - and to cope successfully with infinite numbers of complex life events and stressors. Salutogenesis, therefore, concerns the conditions and resources people use to acquire or "create" health. Thus, as Antonovsky emphasised, salutogenesis is not so concerned with the degree to which individuals or groups possess or lack health. The focus is towards the wider system or context of people's lives and how, on the one hand, this furnishes them with resources to attain health and, on the other, enables them to acquire the skills and capability to access these resources. The salutogenic approach, therefore, considers the extent to which people have power and agency to access structural, environmental, social and economic resources to enable them to attain health. It is consistent with the WHO perspective that health and well-being are shaped and influenced by their surroundings (WHO, 1991), fundamental prerequisites and social determinants.

A salutogenic approach towards understanding prison health is particularly pertinent given that prisoners are likely to be challenged in their ability and capacity to cope and adapt to their circumstances. This ability to withstand imprisonment is likely to impact their health and well-being. However, the penetration of such a viewpoint has not been at the forefront of prison health policymakers or practitioners. The WHO has nonetheless been influential in creating policy frameworks that seek not only to tackle the healthcare challenges posed in prisons but also to advise on how to create prisons that foster salutogenesis. To address the inequalities in the prison population, WHO Europe convened a group to consider how this should be tackled (Gatherer et al., 2005). The settings approach to health promotion was recognised as a way of addressing the health of the prison population after observing the effectiveness of the settings approach in schools, workplaces, hospitals and cities. It was suggested that prisons could be regarded as "another setting in which to advance public health in pursuance of target 14 of WHO's European health for all strategy" (WHO, 1995: 1). Six key conclusions emerged from the meeting: 
1. The prison is a valid and feasible setting for health promotion.

2. Key elements of health promotion in prison include:

- Prevention of deterioration in health

- Enablement and empowerment

- Physical and mental components

- Duty of care to the whole community

- A multidisciplinary and holistic approach

3. All participants recognised health in prison as a priority area for action despite limited resources.

4. Prison services have a duty of care for prisoners and prison staff and to take account of the public health of the wider community.

5. It is important to listen to the views of prisoners and prison staff to meet their needs through a range of effective health promotion strategies.

6. A coordinating centre should be established.

The United Kingdom has been one of the leaders in developing health promotion in prison, with the health-promoting prison concept comprehensively outlined in the English and Welsh strategy "Health Promoting Prisons: A Shared Approach" (Department of Health, 2002). This document used the discourse of a "whole prison" approach with a core philosophy of creating environments that were supportive of health, with an emphasis on the wider determinants of prisoner health to enable individuals to take control of their lives (Graham, 2007). Concurrently, the Scottish Prison Service developed its strategic position for the health-promoting prison (Scottish Prison Service, 2002). Based on core values, such as integrity, honesty and justice as well as principles such as empowerment, equity, partnership and sustainability, their approach was aligned coherently with the original WHO rhetoric and resonated with a broader healthy settings philosophy focused on salutogenesis (Brutus et al., 2012).

The rhetoric has demonstrated a distinct shift to a more salutogenic perspective, but changing practice to incorporate that perspective has been more challenging. Indeed, the WHO has itself acknowledged that policy formulation at a strategic level may not always be implemented effectively in practice (van den Bergh \& Gatherer, 2010). The chapter now considers two questions. First, what makes people healthy and what features of that environment could be adapted to support prisoners develop a stronger sense of coherence? Second, how can prisons support empowerment as a health goal?

\section{What Makes People Healthy in Prison?}

Antonovsky studied the question of what creates health. His answer was formulated in terms of the sense of coherence (SOC) and generalised resistance resources (GRR). The
SOC consists of three dimensions: comprehension, manageability and meaningfulness, reflecting the interaction between the individual and the environment (Eriksson \& Lindström, 2008). GRRs can support a person or community to cope effectively. They can include material resources (e.g. money), genetic (e.g. intelligence), knowledge (e.g. coping strategies) and social (e.g. social network) (Hochwälder, 2019). Both the SOC and GRRs interplay to support individuals' health.

In a prison context, SOC and GRRs have not been fully explored. However, evidence suggests that certain factors can create the conditions for prisoners to maintain positive health and can contribute to their well-being, despite the damaging impacts imprisonment can bring psychologically, socially and materially.

In relation to comprehensibility - one of the dimensions contributing to SOC - it is clear that prison regimes provide structure, give order and predictability. The paradox of the prison routine is evident as it can be highly monotonous and damaging but can benefit some prisoners' mental health and well-being, as it allows prisoners to feel some control. Giddens (1984) noted the importance of routines for maintaining "ontological security" which allow a level of trust in a social environment and Carrabine (2004) argued that routines within prison are held with some significance in that they can alleviate anxiety and unpredictability. Whilst research shows that prisoners broadly object to the regime provided to them, it provides self-assurance, as prisoners can rely on when they will eat, when they will shower, when they will be paid and, of particular importance, when they will receive family visits and time in the gym. Much frustration is caused when these activities are even slightly altered (de Viggiani, 2006b, 2007; Woodall, 2010a).

Manageability and meaningfulness are the two further dimensions of SOC. Prisoners almost unanimously suggest the need for sufficient time out of their cell and adequate access to the outdoors to feel in good health (de Viggiani, 2006b, 2007). Moreover, maintaining regular bouts of both structured and unstructured physical exercise throughout a prisoner's sentence is significant for sustaining and enhancing health (Woodall, 2010b). Social relationships, especially contact with family members, are also intimately intertwined with prisoners' ideas around being healthy (Woodall, 2010b). Relationships are fundamental in prisons between prisoners and staff and create conditions for health, particularly emotional and mental health, to flourish (Crewe et al., 2015; de Viggiani, 2006b). Prisoners may also derive benefits and develop a sense of purpose from taking on peer education and support roles, as these work from an assumption that prisoners may make a positive contribution to health in prison (South et al., 2017). Generally, where relationships are built productively in prison, this can create a more harmonious system. 


\section{Empowerment and Salutogenesis in Prison}

The core values of health promotion are equity, participation and empowerment (Tilford et al., 2003). These basic values are also central elements of the salutogenic concept and its perspective on health (Eriksson \& Lindström, 2008). Empowerment is concerned with individuals and communities having control and power over their circumstances. The relation to the SOC is clear. A person's capability to see that one can manage any situation, independent of whatever is happening in life (Koelen \& Lindstrom, 2005). Indeed, some have argued that "GRRs and SOC could 'empower empowerment' in a scientific sense, and give it a theoretical base and a clear structure" (Koelen \& Lindstrom, 2005: S13).

In a prison context, the notion of empowerment is complex. While empowering prisoners has never been an accepted pursuit in prison systems, even regarded as "morally questionable and politically dangerous" (The Aldridge Foundation and Johnson, 2008: 2), there is a growing recognition that prisons should be "supportive and empowering" (de Viggiani et al., 2005: 918). Empowerment is still an idea of significance for health promotion and should be central to the development of the health-promoting prison. This commitment has been demonstrated by the Scottish Prison Service (2002) but is yet to transfer to other countries. While there is no consensus on what empowerment should entail in the prison context, it is not about jeopardising security or endangering the public. Indeed, Reuss and Wilson's (2000) approach to empowerment within prisons concerns "enabling" and "giving ability to" individuals. This could be through providing education, vocational skill development, parenting skills and managing health conditions. That said, prisons remain settings of tremendous power inequalities (Bosworth \& Carrabine, 2001), rendering empowerment, a primary construct for health promotion, devoid of meaning or even obsolete.

The disempowering nature of prison life is perhaps inevitable, given the absolute mandate to protect the public. That said, some prison reports suggest levels of disempowerment in some establishments being disproportionate and unnecessary. This should be curtailed and, in some instances, can be resolved relatively cost-effectively. Poor relationships tend to be found in prisons - there are examples whereby relationships can be challenging and fraught and where actions towards prisoners by staff (and of course vice-versa) creates health-damaging and pathogenic effects (de Viggiani, 2006b; Woodall, 2020). These relationships can go beyond prisoners and staff and can include how interactions occur with families and prison visitors. For most prisoners' families, prison staff are regarded as the public face of the prison service, embodying the power to punish their relatives (Codd, 2008). Visitors can be treated as a nuisance, a disruption to the rou- tine and a security threat. Prison staff can see visits between a prisoner and his or her family simply as an opportunity to violate prison rules and pass drugs, and sometimes do not attach importance of the visit to the prisoner's and family's well-being and long-term future (Dixey \& Woodall, 2012).

Consequently, staff may be unable to build up extensive rapport or trust with prisoners or their families and therefore resort to a default position which prioritises safety and security. It is the case, of course, that visits have been, and are, an opportunity to breach security, and clearly, prison staff must maintain their remit for control and surveillance. However, the way this is implemented could be reconfigured to foster more supportive environments.

Nevertheless, there are elements of prison life that encourage empowerment, and these should be embraced, continued and replicated where they can be (Woodall, 2020). These include the promotion of people in prison in democratic features of prison life - as the benefits of such civic engagement and participation in prison have been noted elsewhere (Cheney, 2008). In addition, peer support can be an empowering intervention in prisons. Community empowerment and support are at its strongest often when prisoners act to support each other; thereby addressing individuals' personal concerns and fostering a more conducive environment for help-seeking and sharing. The Listener scheme in prisons in England and Wales has a body of evidence which shows individual health gains for those trained as Listeners or befrienders. In several studies, trained prisoners reported that they were "giving something back," doing something constructive with their time in prison and being of benefit to the system, which consequently affected mental health indicators, such as self-esteem, self-worth and confidence (Bagnall et al., 2015; Dhaliwal \& Harrower, 2009; Edgar et al., 2011; Hall \& Gabor, 2004; Levenson \& Farrant, 2002).

Prison architecture and the role of architecture more generally in secure institutions (Golembiewski, 2010) has long been known to have empowering effects. Allies in related areas, such as design and architecture, also support moving health improvement further up the prison agenda, with prison design policies that include health impact assessments (Awofeso, 2011). The Halden prison in Norway is perhaps the most well-known example of a prison designed to be more humane, with health improvement an explicit goal (Woodall et al., 2014). There is much to be transferred from other contexts - other researchers have shown how the design and architecture of psychiatric settings can provide SOC (Golembiewski, 2010). As an example, prison designs should consider:

1. Comprehensibility: Controlling the size of spaces and the numbers of people interacting within them, which is highly pertinent in prisons in relation to overcrowding. 
2. Manageability: Allowing people in prison to exercise control over their environment, such as providing space for recreation and access to natural light.

3. Meaningfulness: Enriching the environment with aesthetic considerations as well as providing good spaces for visitors.

\section{Conclusion}

This chapter has sought to present and debate how prison health rhetoric, policy and practice have for too long been skewed by a long-standing pre-occupation with a pathogenic view of prisoner health. This position - principally informed by epidemiology, medicine and psychiatry - has informed and driven how prison health has been commissioned and delivered internationally. This reactive healthcare orientation is perhaps unsurprising given the poor health status of many people in prison. There is, however, growing recognition of the need to advance a more sophisticated salutogenic approach towards prison health policy and practice, as a strategy that begins to tackle the root causes of health, criminality and inequality synergistically. Several agencies are beginning to advocate and subscribe to this position. The chapter has emphasised that while the health of prisoners is influenced by material and social factors beyond their control, a salutogenic approach offers an alternative way of delivering public health and health promotion in prisons. It does require political commitment, nonetheless, to acknowledge the health-limiting effects of purely preventive prison healthcare policies and the fundamental impact of social inequality and material deprivation as determinants of ill-health and criminality. Providing communities and societies with agency over their health and well-being, and endowing them with the human, cultural and material capital to achieve this, is the only genuine way to begin to develop meaningful public health strategies that transcend all social settings. Undoubtedly, the application of salutogenesis to the prison setting is in its infancy. We therefore anticipate and hope that future research, policy and practice are framed by this valuable theoretical perspective, leading to more sustained and effective measures to improve the health of people in criminal justice settings and to reduce inequalities encountered by these populations.

\section{References}

Antonovsky, A. (1979). Health, stress and coping. Jossey-Bass Publishers.

Awofeso, N. (2011). Disciplinary architecture: Prison design and prisoners' health. Hektoen International: A Journal of Medical Humanities, 3, 1-4.
Bagnall, A.-M., et al. (2015). A systematic review of the effectiveness and cost-effectiveness of peer education and peer support in prisons. BMC Public Health, 15, 1-30.

Baybutt, M., \& Chemlal, K. (2016). Health-promoting prisons: Theory to practice. Global Health Promotion, 23, 66-74.

Baybutt, M., Hayton, P., \& Dooris, M. (2010). Prisons in England and Wales: An important public health opportunity? In J. Douglas, S. Earle, S. Handsley, L. Jones, C. Lloyd, \& S. Spurr (Eds.), A reader in promoting public health. Challenge and controversy (2nd ed., pp. 134-142). Open University Press.

Bennett, J. (2014). Resisting the audit explosion: The art of prison inspection. The Howard Journal of Criminal Justice, 53, 449-467.

Bentham, J. (1864). Theory of legislation. Trubner and Co.

Bosworth, M. (2002). The US federal prison system. Sage.

Bosworth, M., \& Carrabine, E. (2001). Reassessing resistance. Race, gender and sexuality in prison. Punishment \& Society, 3, 501-515.

Breslow, L. (1999). From disease prevention to health promotion. Journal of the American Medical Association, 281, 1030-1033.

Brubaker, B. H. (1983). Health promotion a linguistic analysis. Advances in Nursing Science, 5, 1-14.

Brutus, L., et al. (2012). Better health, better lives for prisoners: A framework for improving the health of Scotland's prisoners. ScotPHN, SHPMG, Scottish Prison Service.

Caraher, M., Dixon, P., Hayton, P., Carr-Hill, R., McGough, H., \& Bird, L. (2002). Are health-promoting prisons an impossibility? Lessons from England and Wales. Health Education, 102, 219-229.

Carrabine, E. (2004). Power, discourse and resistance: A genealogy of the Strangeway prison riot. Ashgate.

Cavadino, M., \& Dignan, J. (2006). Penal policy and political economy. Criminology \& Criminal Justice, 6, 435-456.

Charles, A., \& Draper, H. (2012). 'Equivalence of care' in prison medicine: Is equivalence of process the right measure of equity? Journal of Medical Ethics, 38, 215-218.

Cheney, D. (2008). Prisoners as citizens in a democracy. The Howard Journal of Criminal Justice, 47, 134-145.

Codd, H. (2008). In the shadow of prison. Families, imprisonment and criminal justice. Willan Publishing.

Crewe, B., Liebling, A., \& Hulley, S. (2015). Staff-prisoner relationships, staff professionalism, and the use of authority in public-and private-sector prisons. Law \& Social Inquiry, 40, 309-344.

de Viggiani, N. (2006a). A new approach to prison public health? Challenging and advancing the agenda for prison health. Critical Public Health, 16, 307-316.

de Viggiani, N. (2006b). Surviving prison: Exploring prison social life as a determinant of health. International Journal of Prisoner Health, 2, 71-89.

de Viggiani, N. (2007). Unhealthy prisons: Exploring structural determinants of prison health. Sociology of Health \& Illness, 29, $115-135$

de Viggiani, N., Orme, J., Powell, J., \& Salmon, D. (2005). New arrangements for prison health care provide an opportunity and a challenge for primary care trusts. British Medical Journal, 330, 918.

Department of Health. (2002). Health promoting prisons: A shared approach. Crown.

Dhaliwal, R., \& Harrower, J. (2009). Reducing prisoner vulnerability and providing a means of empowerment: Evaluating the impact of a listener scheme on the listeners. The British Journal of Forensic Practice, 11, 35-43.

Dixey, R., \& Woodall, J. (2012). The significance of 'the visit' in an English category-B prison: Views from prisoners, prisoners' families and prison staff. Community, Work \& Family, 15, 29-47.

Downie, R. S., Tannahill, C., \& Tannahill, A. (1996). Health promotion. Models and values. Oxford University Press. 
Edgar, K., Jacobson, J., \& Biggar, K. (2011). Time well spent: A practical guide to active citizenship and volunteering in prison. Prison Reform Trust Prison Reform Trust.

Eriksson, M., \& Lindström, B. (2008). A salutogenic interpretation of the Ottawa Charter. Health Promotion International, 23, 190-199. https://doi.org/10.1093/heapro/dan014

Ewing, B. (2018). Recent work on punishment and criminogenic disadvantage. Law and Philosophy, 37, 29-68.

Gatherer, A., Møller, L., \& Hayton, P. (2005). The World Health Organization European health in prisons project after 10 years: Persistent barriers and achievements. American Journal of Public Health, 95, 1696-1700.

Giddens, A. (1984). The constitution of society. Outline of the theory of structuration. Polity Press.

Golembiewski, J. A. (2010). Start making sense: Applying a salutogenic model to architectural design for psychiatric care. Facilities, $28,100-117$.

Graham, L. (2007). Prison health in Scotland. A health care needs assessment. Scottish Prison Service.

Hall, B., \& Gabor, P. (2004). Peer suicide prevention in a prison. Crisis, $25,19-26$.

Harding, R. (2006). Are prison inspections effective? Prison Service Journal, 167, 15-19.

Hardwick, N. (2016). Inspecting the prison. In Y. Jewkes, B. Crewe, \& J. Bennett (Eds.), Handbook on prisons (pp. 641-658). Routledge.

HMIP. (1996). Patient or prisoner? A new strategy for health care in prisons. Home Office.

Hochwälder, J. (2019). Sense of coherence: Notes on some challenges for future research. SAGE Open, 9, 2158244019846687. https://doi. org/10.1177/2158244019846687

Ismail, N., Woodall, J., \& de Viggiani, N. (2019). Using laws to further public health causes: The healthy prisons agenda. Global Health Promotion. https://doi.org/10.1177/1757975918811098

King, P. M. (1994). Health promotion: The emerging frontier of nursing. Journal of Advanced Nursing, 20, 209-218.

Koelen, M. A., \& Lindstrom, B. (2005). Making healthy choices easy choices: The role of empowerment. European Journal of Clinical Nutrition, 59, S10-S16.

Levenson, J., \& Farrant, F. (2002). Unlocking potential: Active citizenship and volunteering by prisoners. Probation Journal, 49, 195-204.

Marmot, M., Allen, J., Boyce, T., Goldblatt, P., \& Morrison, J. (2020). Health equity in England: The Marmot review 10 years on. Institute of Health Equity.

Marmot, M., Friel, S., Bell, R., Houweling, T. A., \& Taylor, S. (2008). Closing the gap in a generation: Health equity through action on the social determinants of health. The Lancet, 372, 1661-1669.

Meek, R. (2018). A sporting chance. An independent review of sport in youth and adult prisons. Ministry of Justice.

Mittelmark, M. B., \& Bauer, G. F. (2017). The meanings of salutogenesis. In The handbook of salutogenesis (pp. 7-13). Springer.

Mittelmark, M. B., \& Bull, T. (2013). The salutogenic model of health in health promotion research. Global Health Promotion, 20, 30-38.

Morris, T., \& Morris, P. (1963). Pentonville: A sociological study of an English prison. Routledge.

Morse, S. J. (1975). The twilight of welfare criminology: A reply to Judge Bazelon. Southern California Law Review, 49, 1247.

Rawls, J. (1973). A theory of justice. Oxford University Press.

Reuss, A., \& Wilson, D. (2000). The way forward. In D. Wilson \& A. Reuss (Eds.), Prison(er) education (pp. 172-182). Waterside Press.

Revolving Doors. (2017). Rebalancing act. Revolving Doors.

Roberts, D. (2009). Social harm and crime at a global level. Centre for Crime and Justice Studies.
Scottish Prison Service. (2002). The health promoting prison. A framework for promoting health in the Scottish Prison Service. Health Education Board for Scotland.

Sim, J. (1990). Medical power in prisons. Open University Press.

Smith, C. (2002). Punishment and pleasure: Women, food and the imprisoned body. The Sociological Review, 50, 197-211.

South, J., Bagnall, A.-M., \& Woodall, J. (2017). Developing a typology for peer education and peer support delivered by prisoners. Journal of Correctional Health Care, 23, 214-229.

Squires, N. (1996). Promoting health in prisons. British Medical Journal, 313, 1161.

Sykes, G. M. (1958). The society of captives: A study of a maximum security prison. Princeton University Press.

The Aldridge Foundation, \& Johnson, M. (2008). The user voice of the criminal justice system. The Aldridge Foundation.

Tilford, S., Green, J., \& Tones, K. (2003). Values, health promotion and public health. Centre for Health Promotion Research, Leeds Metropolitan University.

UN General Assembly. (1966). International Covenant on Economic, Social and Cultural Rights, General Assembly 21st Session. GA Res 2200A (XXI), Part III, Article 12. https://undocs.org/en/A/ RES/2200(XXI). Accessed 27 Apr 2020.

United Nations. (1990). Basic principles for the treatment of prisoners. Adopted and proclaimed by General Assembly resolution 45/111 of 14 December 1990. United Nations.

van den Bergh, B. J., \& Gatherer, A. (2010). The potential of practical checklists in successful health policy review and implementation. Public Health, 124, 640-642.

van Zyl Smit, D. (2010). Regulation of prison conditions. Crime and Justice, 39, 503-563.

WHO. (1986). Ottawa Charter for health promotion. Health Promotion, 1, iii-v. https://doi.org/10.1093/heapro/1.4.405

WHO. (1991). Third international conference on health promotion, Sundsvall, Sweden. WHO.

WHO. (1995). Health in prisons. Health promotion in the prison setting. Summary report on a WHO meeting, London 15-17 October 1995. WHO.

WHO. (2016). Prison and health: Factsheet. WHO.

WHO. (2020). Prisons and health: partnership for health in the criminal justice system. http://www.euro.who.int/en/health-topics/healthdeterminants/prisons-and-health/partners. Accessed 22 Apr 2020.

Woodall, J. (2010a). Control and choice in three category-C English prisons: Implications for the concept and practice of the health promoting prison (Unpublished $\mathrm{PhD}$ thesis). Leeds Metropolitan University.

Woodall, J. (2010b). Exploring concepts of health with male prisoners in three category-C English prisons. International Journal of Health Promotion and Education, 48, 115-122.

Woodall, J. (2020). Health promotion co-existing in a high-security prison context: A documentary analysis. International Journal of Prisoner Health. https://doi.org/10.1108/IJPH-09-2019-0047

Woodall, J., de Viggiani, N., Dixey, R., \& South, J. (2014). Moving prison health promotion along: Toward an integrative framework for action to develop health promotion and tackle the social determinants of health. Criminal Justice Studies, 27, 114-132.

Woodall, J., \& Freeman, C. (2019). Promoting health and well-being in prisons: An analysis of one year's prison inspection reports. Critical Public Health, 1-12. https://doi.org/10.1080/09581596.2019.1612 516 
Open Access This chapter is licensed under the terms of the Creative Commons Attribution 4.0 International License (http://creativecommons. org/licenses/by/4.0/), which permits use, sharing, adaptation, distribution and reproduction in any medium or format, as long as you give appropriate credit to the original author(s) and the source, provide a link to the Creative Commons license and indicate if changes were made.

The images or other third party material in this chapter are included in the chapter's Creative Commons license, unless indicated otherwise in a credit line to the material. If material is not included in the chapter's Creative Commons license and your intended use is not permitted by statutory regulation or exceeds the permitted use, you will need to obtain permission directly from the copyright holder.

(c) (1) 